\title{
Sleeve Gastrectomy in the Elderly
}

\author{
Nadav Nevo ${ }^{a}$ Shai Meron Eldar ${ }^{a, b} \quad$ Yonatan Lessing ${ }^{a} \quad$ Edmond Sabo ${ }^{c}$ \\ Ido Nachmany ${ }^{a}$ David Hazzan ${ }^{d}$ \\ ${ }^{a}$ General Surgery Division, Tel-Aviv Sourasky Medical Center, Affiliated to the Sackler \\ Faculty, Tel-Aviv-Yafo, Israel; ${ }^{b}$ Bariatric Surgery Unit, The Tel-Aviv Sourasky Medical Center \\ of Medicine, Tel Aviv University, Tel-Aviv-Yafo, Israel; ' ${ }^{\circ}$ Department of Pathology, Technion, \\ Haifa, Israel; dGeneral Surgery Department C, Sheba Medical Center, Ramat Gan, Israel
}

\author{
Keywords \\ Bariatric surgery · Sleeve gastrectomy · Elderly
}

\begin{abstract}
Background: Even though risks are higher and long-term results may be less favorable, the elderly obese can still benefit from bariatric surgery. Whether the higher surgical risk is worth the benefits is yet to be determined. Materials and Methods: We reviewed our database and identified all patients aged 65 or older who underwent sleeve gastrectomy between May 2010 and November 2015. We documented patient demographics, obesity-related comorbidities, body mass index (BMI) before and after the procedure, percent excess weight loss, comorbidity improvement or resolution, length of follow-up, postoperative complications, re-operations, and length of hospital stay. We compared our study group to a control group of sleeve gastrectomy patients under the age of 65. Results: Sixty-six patients (mean age $67.6 \pm 2.6$ years) underwent laparoscopic sleeve gastrectomy. Patients achieved an average of $53.5 \%$ excess BMI loss (EBMIL) after 21 months of follow-up. EBMIL was inferior to that achieved by the control group (EBMIL 77.3\%, $p<0.0001$ ). Elderly patients showed significant improvement or resolution in all obesity-related comorbidities. Complication and re-operation rates were similar between the 2 groups. Conclusion: In an elderly population, laparoscopic sleeve gastrectomy is safe and effective, yet weight loss outcomes are more modest when compared to a younger surgical population. Carefully selected elderly patients can benefit from bariatric surgery.


Nevo et al.: Sleeve Gastrectomy in the Elderly

\section{Introduction}

Obesity has reached worldwide pan-endemic magnitude and is one of the most significant combat targets of our generation. While the prevalence of obesity in the USA has plateaued over the past 5 years, it remains that $68 \%$ of the adult US population are overweight $\left(\mathrm{BMI}>25 \mathrm{~kg} / \mathrm{m}^{2}\right.$ ) and $35.7 \%$ are obese (BMI $>30 \mathrm{~kg} / \mathrm{m}^{2}$ ) [1, 2]. As life expectancy increases globally, seniors are the fastest-growing population in the world and are demonstrating the effects of an obesogenic environment [3]. The elderly also have a greater propensity to obesity-related comorbidities, given that aging is an additional predisposing factor for many of these conditions, and older obese individuals are at greater risk of premature obesity-related death compared to their younger counterparts [4]. Bariatric surgery has been demonstrated to be safe and effective in achieving sustainable weight loss and improving or resolving obesity-related comorbidities [5-8]. Laparoscopic sleeve gastrectomy (LSG) - with its high efficacy and low complication rates - has gained popularity during the past decade worldwide and is currently second in popularity only to roux-en-y gastric bypass [9].

With increasing experience in surgical technique and perioperative care, bariatric surgery is being pushed to its limits, and age is one of these limits being questioned. Until recently, age was considered a relative contraindication to bariatric surgery [10] due to questionable benefits and less tolerable complications and morbidity [11], but we now witness more and more bariatric procedures performed in the elderly population. In this age group it is mandatory to carefully select eligible candidates in good physical condition; otherwise they might not withstand complications. Since their life expectancy is shorter, the true benefit from bariatric surgery is difficult to judge. Another point worth consideration in the elderly is whether longstanding comorbidities such as diabetes and hypertension result in irreversible end-organ damage and whether remission in these aspects gives a true benefit to the patient.

Data from nonbariatric surgery literature has demonstrated that elderly patients are at increased risk of perioperative morbidity and mortality. The loss of physiological reserve and high likelihood of medical comorbidity associated with aging greatly reduce the elderly patient's tolerance of operative procedures. Flum etal. [12] and Livingston et al. [13, 14] briefly addressed the safety of bariatric surgery in the elderly, showing that patients aged 65 years or older had a threefold higher perioperative mortality rate when compared to younger patients. More recent studies have demonstrated a lower risk in this setting, when bariatric patients are carefully selected, medically optimized preoperatively, and when procedures are performed by experienced laparoscopic bariatric surgeons [15-17]. Although weight loss and metabolic outcomes in older obese patients have been less dramatic than in younger adults, the benefits of bariatric surgery in this subgroup include an improved quality of life and decreased mortality [18-20]. Existing reports include small cohorts of patients aged $>65$ years.

The aim of this study was to learn more about the feasibility of sleeve gastrectomy in the elderly population, the validity of the indications, the associated complications and morbidity, and the operative results after surgery.

\section{Materials and Methods}

We retrospectively reviewed our prospectively collected database for all patients who underwent LSG in the bariatric surgery unit of the Tel-Aviv Sourasky medical center. We then selected patients who were 65 years old or older at the time of surgery. We compared this study group to a control group of sleeve gastrectomy patients younger than 65 at the time of surgery. 
Nevo et al: Sleeve Gastrectomy in the El

Table 1. Patient demographics

\begin{tabular}{lccc}
\hline & Study group & Control group & $p$ value \\
\hline Patients & 66 & 65 & $\mathrm{~ns}$ \\
Age, years & $67.6 \pm 2.6$ & $38.4 \pm 11$ & $<0.0001$ \\
Male/female & $25 / 41(38 / 62)$ & $26 / 39(40 / 60)$ & $\mathrm{ns}$ \\
BMI, $\mathrm{kg} / \mathrm{m}^{2}$ & $44.2 \pm 7$ & $42.7 \pm 5.4$ & $\mathrm{~ns}$ \\
Weight, $\mathrm{kg}$ & 119.4 & 122.4 & $\mathrm{~ns}$ \\
\hline
\end{tabular}

Data are presented as $n(\%)$ or mean \pm SD, unless otherwise indicated. BMI, body mass index; ns, not significant.

Table 2. Comorbidities

\begin{tabular}{llll}
\hline & Study group & Control group & $p$ value \\
\hline Hypertension & $50(75.8)$ & $16(24.6)$ & $<0.0001$ \\
Diabetes & $42(63.6)$ & $15(23.1)$ & $<0.0001$ \\
Hyperlipidemia & $35(53)$ & $15(23.1)$ & $<0.0004$ \\
OSA & $21(31.8)$ & $11(16.9)$ & $<0.000$ \\
Orthopedic & $29(43.9)$ & $17(26.1)$ & 0.047 \\
\hline
\end{tabular}

Data are presented as $n(\%)$. OSA, obstructive sleep apnea.

All patients were preoperatively assessed by a multidisciplinary team, and the criteria used for LSG were based on the established Guidelines for Metabolic and Bariatric Surgery a body mass index (BMI) $>40 \mathrm{~kg} / \mathrm{m}^{2}$ or a BMI $>35 \mathrm{~kg} / \mathrm{m}^{2}$ with obesity-related comorbidities.

We looked at patient demographics, preoperative BMI, obesity-related comorbidities, operative and postoperative course, re-admissions and re-operations, and medium-term outcomes regarding body weight and comorbidity resolution. Weight loss failure or weight regain were defined as a BMI $>35$ or/and excess weight loss $<50 \%$. Excluded from this study were patients with less than 6 months of follow-up.

\section{Statistical Analysis}

The Kolmogorov Smirnov test was used to define normal and non-normal distribution of variables. For comparison of 2 groups, $\chi^{2}$ analysis and Fisher's exact test were used when appropriate for qualitative data, and the Student $t$ test (for normal variables) or MannWhitney U test (for non-normal variables) for quantitative data. Equality of variances in normally distributed variables was examined by the Levene test. For the comparison of group pairs the paired $t$ test was used. For multivariate analysis the forward stepwise logistic regression technique was applied. A probability of 0.05 or less was accepted as statistically significant.

\section{Results}

Between May 2010 and November 2015, 66 patients over the age of 65 underwent sleeve gastrectomy for morbid obesity in our institution of which only 5 were lost to follow-up.

Demographic and clinical characteristics of the 2 study groups are presented in Table 1. The male to female ratio, the preoperative weight, and preoperative BMI of the 2 groups was 
Table 3. Complications (Clavien-Dindo $\geq 3$ )

\begin{tabular}{llll}
\hline & $\begin{array}{l}\text { Study group } \\
(3 / 66)\end{array}$ & $\begin{array}{l}\text { Control group } \\
(3 / 65)\end{array}$ & $\begin{array}{l}p \text { value } \\
0.976\end{array}$ \\
\hline $\begin{array}{lll}\text { Early } \\
\text { Leak/abscess }\end{array}$ & 0 & & \\
Bleeding/hematoma & $2(3)$ & $1(1.5)$ & 0.319 \\
Other & $1(1.5)$ & $1(1.5)$ & 0.562 \\
Re-operation & $2(3)$ & $1(1.5)$ & 1 \\
\hline Late & & & 0.562 \\
GERD & $5(7.5)$ & $3(4.6)$ & 0.469 \\
Dysphagia/stricture & $3(4.5)$ & $2(3)$ & 0.651 \\
POVH & 0 & $1(1.5)$ & 0.319 \\
\hline
\end{tabular}

Data are presented as $n(\%)$. Late complications $>30$ days. GERD, Gastro esophageal reflux disease. POVH, Postoperative ventral hernia.

Table 4. Comparative outcomes

\begin{tabular}{lccc}
\hline & $\begin{array}{l}\text { Control group } \\
(65 / 65)\end{array}$ & $\begin{array}{l}\text { Study group } \\
(61 / 66)\end{array}$ & $p$ value \\
\hline Follow-up, months & $21 \pm 16.8$ & $17 \pm 11.9$ & 0.22 \\
BMI, kg/m 2 & $29.3 \pm 4.7$ & $34.2 \pm 5.4$ & $<0.0001$ \\
EBMIL, \% & 53.5 & 77.3 & $<0.0001$ \\
Objective failure & $21(32.8)$ & $7(10.8)$ & $<0.0001$ \\
Diabetes improvement/resolution & $10 / 15(66.6)$ & $25 / 42(59.5)$ & 0.002 \\
Hypertension improvement/resolution & $9 / 16(56.2)$ & $22 / 50(44)$ & $<0.0001$ \\
Hyperlipidemia improvement/resolution & $5 / 15(33.3)$ & $26 / 35(74.2)$ & 0.59 \\
Orthopedic improvement & $14 / 17(82.3)$ & $14 / 29(48.2)$ & 0.003 \\
LOS, days & $3 \pm 1.7$ & $4 \pm 2$ & 0.28 \\
\hline
\end{tabular}

Data are presented as mean \pm SD or $n(\%)$, unless otherwise indicated. Objective failure: defined as BMI $>35$ or EWL $<50 \%$. BMI, body mass index; EBMIL, excess BMI loss; LOS, length of stay.

comparable. Comorbidities, which in many cases are the main clinical or metabolic indication for surgery, were much more significant in the study group, particularly hypertension, diabetes mellitus, dyslipidemia, and pulmonary pathology (Table 2).

Intra- and postoperative complications occurred in 7 patients $(10.6 \%)$ of the elderly patients (Table 3). Postoperative bleeding was noted in 6 patients, 2 of whom required blood transfusion and 1 required re-operation; in 1 case tracheostomy was necessary due to difficulty in weaning from mechanical ventilation.

The mean length of hospital stay after surgery was 4 days for the study group. The average follow-up period was 21 months from surgery and ranged between 6 and 47 months after surgery (Table 4). Mean BMI on follow-up was 34.2 ( \pm 5.4 ) with an excess BMI loss (EBMIL) of $53.5 \%$ and objective failure rate (defined as BMI $>35$ or excess weight loss $<50 \%$ ) of $32.8 \%$. Diabetes resolved or improved in 25/42 patients (59.5\%), hypertension in 22/50 patients (44\%), and hyperlipidemia in $26 / 35$ patients $(74.2 \%)$, and orthopedic complaints improved in $14 / 29$ cases $(48.2 \%)$.

For the control group, mean length of stay after surgery was 3 days (2-13 days). Intraand postoperative complications occurred in 7 patients (10.7\%). In 1 case an additional sple- 
Nevo et al.: Sleeve Gastrectomy in the Elderly

nectomy was required due to intraoperative bleeding, pneumonia occurred in 1 case, intrabdominal abscess was noted in 1 case and postoperative bleeding occurred in 5 patients, of whom only 1 case required blood transfusion

The average follow-up period was 17 months from surgery, mean BMI at follow-up was 29.3, with an EBMIL of 77.3 and objective failure rate of 10.8\%. Diabetes resolved or improved in $10 / 15$ patients $(66.6 \%)$, hypertension in $9 / 16$ patients $(56.2 \%)$ (in 1 case hypertension was diagnosed following the surgical procedure), and hyperlipidemia in 26/35 patients (74.2\%), and orthopedic complaints improved in 14/17 cases (82.3\%).

When comparing the 2 groups in our present study, patients in the elderly group were slightly heavier than those in the control group prior to surgery (Table 1). Their average BMI was 44.2 compared to 42.7 , yet this had no statistical significance $(p=0.17)$. Associated comorbidities such as hypertension and diabetes were significantly more frequent in the senior group as opposed to the younger group (Table 2) (75.8 vs. $24.6 \%$ and 63.6 vs. $23.1 \%$, respectively) ( $p<0.0001)$.

The effect of the surgical procedure on our 2 groups of patients is represented in Table 4. The BMI of the younger age group dropped after sleeve gastrectomy from an average of 42.7 to an average of 29.3 ( $p<0.0001)$, while that of the senior group dropped after the same procedure from an average of $44.2 \pm 7.0$ to an average of $34.2 \pm 5.4(p<0.0001)$. EBMIL was 77.3 compared to 53.5 in the senior group $(p<0.0001)$, and objective failure was seen in $10.8 \%$ in the younger group compared to $32.8 \%$ in our study group $(p<0.0001)$.

\section{Discussion}

Several factors played a role in the prosperity of bariatric surgery in general, and more specifically enabling its adoption in the elderly obese [21]. The birth of laparoscopy and the development of laparoscopic technology made bariatric surgery less invasive [22, 23], with rapid evolution in surgical technique, and finally, progress in perioperative multidisciplinary treatment enabling speedy and early recovery from surgery [24].

The vast experience gained over the last decade elevated the safety profile of these procedures, and surgeons became more comfortable in offering these procedures to older candidates.

Sleeve gastrectomy, with its high efficacy and relatively low morbidity and mortality, became the procedure of choice for many bariatric surgeons in this high-risk population. Guidelines support similar indications for surgery in the elderly, and with much higher rates of comorbidities, the demand for bariatric surgery is even stronger.

We found a comparable length of hospital stay and similar complication and re-operation rates, indicating a similarly high safety profile for the elderly obese. Comparable complication rates are further reported by several studies and underlined in a meta-analytical review [21, 24-26]. Several previous publications showed similar weight loss at 1 year following LSG in older patients $[24,25]$.

In our study, postoperative weight loss and BMI decrease are more pronounced in the younger age group, but still remain significant enough in the senior group (Table 4). These results are similar to those of Luppi et al. [26] and are generally supported by a meta-analytical review reported by Wang et al. [21]. Several mechanisms have been offered to explain the more modest weight loss in the elderly. This can be explained by the low metabolic rate in the elderly population [27, 28], age-related decrease in fat oxidation [29], weakened lipolytic activity of postmenopausal women that compose the majority of the older group, and/or lower levels of physical activity executed in the older age group [30]. 
Comparable to the study of Luppi et al. [26] but in contrast to the meta-analytic review of Wang et al. [21], comorbidities were more frequent and more significant in the senior group than in the younger group who had surgery (Table 2). This fact strongly supports the extension of surgery to the older age group. According to the meta-analytical report, the major and significant comorbidities were similar in the younger and older age groups. When considering the postoperative improvement or resolution in comorbidities following surgery, it seems to be beyond any doubt that the indication for surgery is fully present even at an advanced age. This improvement after the age of 65 years is significant and is witnessed in all comorbidities.

When all the factors are considered - preoperatively, during surgery, and postoperatively we believe bariatric surgery is fully indicated for older patients. This study supports the data published previously, that older patients withstand surgery equally well in terms of complications, morbidity, and mortality, and that surgical outcomes are worth the surgical risk.

In this era as the population is aging, the wellbeing and improved health of patients operated on in their late 60 s and early 70 s can continue on into their 80 s and 90 s.

\section{Statement of Ethics}

This study was approved by the Tel-Aviv Sourasky Medical Center institutional review board (IRB). Formal consent is not required for this type of study.

\section{Disclosure Statement}

All authors have no conflicts of interest or financial ties to disclose.

\section{Funding Sources}

The authors received no financial support for the research.

\section{Author Contributions}

N.N.: data acquisition, statistical analysis, and drafting the manuscript. S.M.E.: study conception, critical revision of the manuscript, and surgeon. Y.L. and E.S.: data acquisition and statistical analysis. I.N.: surgeon and data acquisition. D.H.: study conception and critical revision of the manuscript.

\section{References}

1 Flegal KM, Carroll MD, Ogden CL, Curtin LR. Prevalence and trends in obesity among US adults, 1999-2008. JAMA. 2010 Jan;303(3):235-41.

2 Ogden CL, Carroll MD, Kit BK, Flegal KM. Prevalence of obesity in the United States. NCHS Data Brief, No. 82, January 2012. pp. 1-8.

3 Peeters A, Barendregt JJ, Willekens F, Mackenbach JP, Al Mamun A, Bonneux L; NEDCOM, the Netherlands Epidemiology and Demography Compression of Morbidity Research Group. Obesity in adulthood and its consequences for life expectancy: a life-table analysis. Ann Intern Med. 2003 Jan;138(1):24-32.

4 Buchwald H, Avidor Y, Braunwald E, Jensen MD, Pories W, Fahrbach K, et al. Bariatric surgery: a systematic review and meta-analysis. JAMA. 2004 Oct;292(14):1724-37. 
Nevo et al.: Sleeve Gastrectomy in the Elderly

5 Flum DR, Belle SH, King WC, Wahed AS, Berk P, Chapman W, et al.; Longitudinal Assessment of Bariatric Surgery (LABS) Consortium. Perioperative safety in the longitudinal assessment of bariatric surgery. N Engl J Med. 2009 Jul;361(5):445-54.

6 Brethauer SA, Hammel JP, Schauer PR. Systematic review of sleeve gastrectomy as staging and primary bariatric procedure. Surg Obes Relat Dis. 2009 Jul-Aug;5(4):469-75.

7 Hutter MM, Schirmer BD, Jones DB, Ko CY, Cohen ME, Merkow RP, et al. First report from the American College of Surgeons Bariatric Surgery Center Network: laparoscopic sleeve gastrectomy has morbidity and effectiveness positioned between the band and the bypass. Ann Surg. 2011 Sep;254(3):410-20; discussion 420-2.

8 Gloy VL, Briel M, Bhatt DL, Kashyap SR, Schauer PR, Mingrone G, et al. Bariatric surgery versus non-surgical treatment for obesity: a systematic review and meta-analysis of randomised controlled trials. BMJ. 2013 Oct; 347:f5934.

9 Livingston EH, Langert J. The impact of age and Medicare status on bariatric surgical outcomes. Arch Surg. 2006 Nov;141(11):1115-20; discussion 1121.

10 Printen KJ, Mason EE. Gastric bypass for morbid obesity in patients more than fifty years of age. Surg Gynecol Obstet. 1977 Feb;144(2):192-4.

11 Finks JF, Kole KL, Yenumula PR, English WJ, Krause KR, Carlin AM, et al.; Michigan Bariatric Surgery Collaborative, from the Center for Healthcare Outcomes and Policy. Predicting risk for serious complications with bariatric surgery: results from the Michigan Bariatric Surgery Collaborative. Ann Surg. 2011 Oct;254(4):63340.

12 Flum DR, Salem L, Elrod JA, Dellinger EP, Cheadle A, Chan L. Early mortality among Medicare beneficiaries undergoing bariatric surgical procedures. JAMA. 2005 Oct;294(15):1903-8.

13 Livingston EH, Huerta S, Arthur D, Lee S, De Shields S, Heber D. Male gender is a predictor of morbidity and age a predictor of mortality for patients undergoing gastric bypass surgery. Ann Surg. 2002 Nov;236(5):5768.2

14 Livingston EH, Langert J. The impact of age and Medicare status on bariatric surgical outcomes. Arch Surg. 2006;141:1115-20.

15 Hallowell PT, Stellato TA, Schuster M, Graf K, Robinson A, Jasper JJ. Avoidance of complications in older patients and Medicare recipients undergoing gastric bypass. Arch Surg. 2007;142:506-12.

16 Quebbemann B, Engstrom D, Siegfried T, Garner K, Dallal R. Bariatric surgery in patients older than 65 years is safe and effective. Surg Obes Relat Dis. 2005;1(4):389-93.

17 Taylor CJ, Layani L. Laparoscopic adjustable gastric banding in patients $\geq 60$ years old: is it worthwhile? Obes Surg. 2006 Dec;16(12):1579-83.

18 Busetto L, Angrisani L, Basso N, Favretti F, Furbetta F, Lorenzo M; Italian Group for Lap-Band. Safety and efficacy of laparoscopic adjustable gastric banding in the elderly. Obesity (Silver Spring). 2008 Feb;16(2): 334-8.

19 Frutos MD, Luján J, Hernández Q, Valero G, Parrilla P. Results of laparoscopic gastric bypass in patients older than 55 years old. Obes Surg. 2006 Apr;16(4):461-4.

20 Dunkle-Blatter SE, St. Jean MR, Whitehead C, Strodel W 3rd, Bennotti PN, Still C, et al. Outcomes among elderly bariatric patients at a high-volume center. Surg Obes Relat Dis. 2007 Mar-Apr;3(2):163-9; discussion 169-70.

21 Wang Y, Yi X, Li Q, Zhang J, Wang Z. The effectiveness and safety of sleeve gastrectomy in the obese elderly patients: a systematic review and meta-analysis. Obes Surg. 2016 Dec;26(12):3023-30.

22 Dorman RB, Abraham AA, Al-Refaie WB, Parsons HM, Ikramuddin S, Habermann EB. Bariatric surgery outcomes in the elderly: an ACS NSQIP study. J Gastrointest Surg. 2012 Jan;16(1):35-44.

23 Sampath K, Dinani AM, Rothstein RI. Endoscopic devices for obesity. Curr Obes Rep. 2016 Jun;5(2):251-61.

24 Leivonen MK, Juuti A, Jaser N, Mustonen H. Laparoscopic sleeve gastrectomy in patients over 59 years: early recovery and 12-month follow-up. Obes Surg. 2011 Aug;21(8):1180-7.

25 van Rutte PW, Smulders JF, de Zoete JP, Nienhuijs SW. Sleeve gastrectomy in older obese patients. Surg Endosc. 2013 Jun;27(6):2014-9.

26 Luppi CR, Balagué C, Targarona EM, Mocanu S, Bollo J, Martínez C, et al. Laparoscopic sleeve gastrectomy in patients over 60 years: impact of age on weight loss and co-morbidity improvement. Surg Obes Relat Dis. 2015 Mar-Apr;11(2):296-301.

27 Scozzari G, Passera R, Benvenga R, Toppino M, Morino M. Age as a long-term prognostic factor in bariatric surgery. Ann Surg. 2012 Nov;256(5):724-8.

28 Manini TM. Energy expenditure and aging. Ageing Res Rev. 2010 Jan;9(1):1-11.

29 Toth MJ, Tchernof A. Lipid metabolism in the elderly. Eur J Clin Nutr. 2000 Jun;54(S3 Suppl 3):S121-5.

30 Nicklas BJ, Rogus EM, Goldberg AP. Exercise blunts declines in lipolysis and fat oxidation after dietary-induced weight loss in obese older women. Am J Physiol. 1997 Jul;273(1 Pt 1):E149-55. 